Accepted for publication in the Journal of Materials Engineering and Performance, July

2011- in print December 2011

\title{
Simulation of Viscoplastic Deformation of Low Carbon Steel- Structures at Elevated Temperatures
}

\author{
Y. Sun, K. Maciejewski, and H. Ghonem \\ Mechanics of Materials Research Laboratory \\ Department of Mechanical Engineering and Applied Mechanics \\ University of Rhode Island, Kingston, R.I. 02881, U.S.A
}

\begin{abstract}
The deformation response of a low carbon structural steel subjected to high temperature simulating fire conditions is generated using a viscoplastic material constitutive model which acknowledges the evolution of the material hardening parameters during the loading history. The material model is implemented in an ABAQUS subroutine (UMAT) which requires the determination of the material constants as a function of temperature. Both the temperature dependency and strain-rate sensitivity of the material parameters have been examined by analysis of a single steel beam and a steel-framed structure subjected to temperatures ranging from $300^{\circ} \mathrm{C}-700^{\circ} \mathrm{C}$. Sequentially coupled thermalstress analysis is applied to a structure under simulated fire condition. Results of this analysis show that above a transitional temperature, the deformation of the steel is strainrate dependent. The combined effect of heat flux and loading rate on the complex deformation of a two story steel structure is examined and the significance of employing a viscoplastic material model is discussed.
\end{abstract}

Keywords: Internal State Variables, Viscoplasticity; Hardening; Strain-rate sensitivity; Structural Steel; Finite element analysis

\section{Introduction}

With the advancement of computation technology, engineers tend to adopt more advanced thermal and mechanical simulation techniques to assess the safety and reliability of engineering structures. Advanced numerical analysis allows less simplifications or assumptions for the description of material constitutive behavior, geometric modeling, real boundary conditions and loading, hence leading to a more realistic prediction of the stress/deformation in the studied engineering structure. For example, the deformation response prediction of steel-framed structures under fire conditions was done based on an elasto-plastic beam-column formulation [Liew 1998, Makelainen 1998]; The non-uniform profile of temperature across section of frame members was considered in [Li 1999]; The creep strain model was included in the simulation of steel frames in fire [Wang 1995]; Nonlinear analyses for three-dimensional 
steel frames in fire was presented in [Najjar 1996, Kuma 2004], but without taking into account the strain-rate sensitivity of the steel material at elevated temperature and nonlinear temperature distribution both across section of steel frames and along length of beam-column.

In the present work, viscoplastic constitutive equations [Chaboche 1983 I, Nouailhas 1989] are used to describe the nonlinear behavior of low carbon steel at elevated temperatures. The material parameters in the viscoplastic constitutive equations are modeled as a function of temperature and implemented in ABAQUS subroutine UMAT. The UMAT code is verified by the simulation of tensile tests of monotonic displacement loading at different temperatures and of a fatigue test of cyclic displacement loading. The simulation of single steel beam is conducted to show the effect of loading rate and temperature on the beam deflection. Furthermore, sequentially coupled thermal-stress simulation technique is employed in the finite element analysis of a three-dimensional steel-framed structure. Transient heat transfer analysis is first conducted to obtain the temperature distribution on the steel frames as a function of time. Nodal temperature results from heat transfer analysis are then transferred for structural response analysis. The main focus of the paper is to study the influence of the mechanical behaviors of the steel material on the deformation response of steel structures.

\section{Viscoplastic constitutive equations}

The model described in this section is based on unified constitutive equations in the manner developed by Chaboche and Rousselier [Chaboche 1983 I, Chaboche 1983 II]. This model formulated on the assumption that a viscoplastic potential, $\Omega$, exists in the stress space. A particular form of the viscoplastic potential is [Nouailhas 1989]:

$$
\Omega=\frac{K}{\alpha(n+1)} \exp \left(\alpha\left\langle\frac{\sigma_{v}}{K}\right\rangle^{n+1}\right)
$$

Where $K, n$, and $\alpha$ are material parameters that characterize the rate sensitivity. To describe the viscoplastic behavior, the concept of time-dependent overstress or viscous stress, $\sigma_{v}$, is used. This is given as:

$$
\sigma_{v}=J(\sigma-X)-R-k
$$

Where the tensor $X$ represents the kinematic hardening stress, $R$ and $k$ are scalar variables corresponding to the isotropic hardening stress and the initial yield stress, respectively, and $J(\sigma-X)$, is Von Mises second invariant defined by:

$$
J\left(\sigma_{i j}-X_{i j}\right)=\left(\frac{3}{2}\left(\sigma_{i j}^{\prime}-X_{i j}^{\prime}\right):\left(\sigma_{i j}^{\prime}-X_{i j}^{\prime}\right)\right)^{1 / 2}
$$

Where $\sigma^{\prime}$ and $X^{\prime}$ are the deviatoric parts of the applied stress tensor, $\sigma$, and the back stress tensor, $X$ respectively. The scalar $k$ is a temperature dependent material constant representing the initial size of the elastic domain. Throughout this development, the total strain is partitioned into an elastic component and an inelastic component. The unified viscoplastic equations incorporate the plastic and creep components simultaneously in an inelastic or viscoplastic strain component denoted by $\varepsilon_{p}$ throughout the rest of this paper 
[Chaboche 1983 I, Chaboche 1983 II, Chaboche 1989]. The relation between plastic flow and the viscoplastic potential is determined by means of the normality rule:

$$
d \varepsilon_{p}=\frac{\partial \Omega}{\partial \sigma_{i j}}=d p \frac{3}{2} \frac{\left(\sigma^{\prime}{ }^{\prime}-X^{\prime}{ }^{\prime}\right)}{J_{2}\left(\sigma_{i j}^{\prime}-X^{\prime}{ }_{i j}\right)}
$$

Where the $d p$ is the accumulated plastic strain rate, which is given in terms of effective plastic strain as:

$$
d p=\left(\frac{2}{3} d \varepsilon_{p} d \varepsilon_{p}\right)^{1 / 2}=\left\langle\frac{J_{2}(\sigma-X)-R-k}{K}\right\rangle^{n} \exp \left(\alpha\left\langle\frac{J_{2}(\sigma-X)-R-k}{K}\right\rangle^{n+1}\right)
$$

The kinematic hardening terms, measured by the back stress $X$, describes the internal changes during each inelastic transient. Two terms of back stress describing the phenomena of the Bauschinger effect will be considered here. The first term, $X_{i j}^{1}$, is the short range hardening effect, which is a fast saturated variable. The second term, $X_{i j}^{2}$, is a quasi-linear variable describing the long range hardening effect. Hence, the back stress is defined as:

$$
X_{i j}=X_{i j}^{1}+X_{i j}^{2}
$$

Where each term is described by a general form as [Chaboche 1983 I, Nouailhas 1989]:

$$
\dot{X}_{i j}^{i}=c_{i}\left(\frac{2}{3} a_{i} \dot{\varepsilon}_{i j}^{p}-X_{i j}^{i} \dot{p}\right)-\beta_{i} \mid J\left(X_{i j}^{i}\right)^{r_{i}-1} X_{i j}^{i}
$$

The first term describes the strain hardening as a function of $X$, plastic strain rate and accumulated plastic strain rate. The second term represents processes for bypassing or penetrating barriers at comparable rates and is termed dynamic recovery. The third term, which is strongly temperature-dependent, describes the time-recovery or staticrecovery as a function of $X . c, \alpha, \beta$, and $r$ are material-dependent parameters and $J\left(X_{i j}\right)$ is the second invariant of $X_{i j}$.

The slow evolution of microstructure associated with cyclic hardening or softening of the material can be described by the isotropic hardening variable, $R$, which is the difference in the saturation position after a loading cycle and that corresponding to the monotonic loading for the same plastic strain. This is governed by the following equations:

$$
\begin{gathered}
\dot{R}=b(Q-R) \dot{p} \\
Q=Q_{\max }\left(1-e^{-\mu q}\right) \\
q=\max \left(\left|\varepsilon_{p}\right|, q\right)
\end{gathered}
$$

Where $Q$ and $b$ are the limiting values of the isotropic hardening variable. $Q$ is the saturation limit of $R$ while the constant, $b$, is a temperature and material-dependent parameter describing how fast $\mathrm{R}$ reaches $Q$. This latter parameter can be either a positive value, indicating cyclic hardening, or a negative value, indicating cyclic softening. $Q_{\max }$ is the maximum value of $Q$, and $q$ is the maximum strain achieved during loading, which memorizes the previous plastic strain range [Zaki 2000]. 


\section{Model's Material Parameters}

The material employed in this study is A572 Grade 50 Low Carbon Steel and its microstructure which is shown in Fig. 1, includes pearlite colonies and alpha-ferrite equiaxed grains. The average grain size is $53 \mu \mathrm{m}$ (ASTM 5). Volume fraction of the pearlite phase is $10 \%$.

Figure 1. Optical micrograph of as-received A572 grade 50 steel etched for 5 seconds in 5 vol\% nital. The microstructure is typical of normalized steel, consisting of pearlite colonies (dark phase) and alpha-ferrite (light phase) equiaxed grains. The pearlite colonies have a volume fraction of $10 \%$ and the grain size is 53 microns (ASTM 5).

A series of strain-controlled tests were carried out on the as received steel, at both room and high temperature, to determine the various material parameters described above in order to fully identify the non-linear kinematic hardening model. The mechanical testing was carried out using a servo hydraulic test machine, equipped with a heat induction coil for the high temperature tests. The strain was measured with a quartz rod extensometer.

A monotonic test is carried out, to determine the modulus, $E$, and yield stress, $k$, of the material. Results of this rate at various loading conditions are shown in Fig. 2a. A series of strain-controlled fully reversed cyclic stress-strain tests (fatigue stress ratio $=-1$ ) are performed at strain ranges varying from $\pm 0.2 \%$ to $\pm 1 \%$ strain. A typical cyclic stressstrain curve at $300^{\circ} \mathrm{C}$ is shown in Fig. 2b. These loops are employed to generate the isotropic and kinematic hardening, as well as, viscosity and recovery parameters.

Figure 2. Experimental (Symbol) and numerical (Solid line) stress-strain curves for low carbon steel tested (a) Monotonic stress-strain curves (b) cyclic stress-strain curves at $300^{\circ} \mathrm{C}$, (c) relaxation stress-strain curves at $300^{\circ} \mathrm{C}$ and (d) monotonic stress-strain curves at multiple strain rates at $500^{\circ} \mathrm{C}$. These curves are used to determine the material parameters specified on the graphs.

The isotropic hardening parameter, $b$, is determined from the evolution of the peaks of the cyclic stress-strain curves (Fig. 2b) $Q_{\max }$ and $\mu$ are calculated from the difference in the peak stress of the first cycle and the saturated cycle as a function of the maximum plastic strain achieved during loading [Maciejewski 2009, Nouailhas 1987, Nouailhas 1989, Zaki 2000]. The kinematic stress corresponds to the center of the linear part of the first reversible cyclic loop at each strain range (Fig. 2b). This stress is determined as a function of plastic strain to determine the materials parameters $a_{1}, c_{1}, a_{2}$ and $c_{2}$.

To describe the time-dependent viscous stress term, a strain-controlled monotonic stress-relaxation test is performed, as seen in Fig. 2c. For this, during the periods of holding at a constant total strain, the stress and stress rate as a function of time is acquired. This is used to obtain the viscous stress in terms of plastic strain rate, from which, $n$ and $K$, strain-rate sensitive parameters must be determined [Nouailhas 1989, Chaboche 1989, Lemaitre 1990]. The material constant, $\alpha$, is taken to be the saturation limit of viscous stress for high plastic strain rates. 
Time-dependent recovery parameters, $\beta_{1}, \beta_{2}$, are determined from the linear portion of the stress time curve. In this region it is assumed that $R, k$ and viscous stress are constant and the time dependent stress is only coming from the time dependent back stress. These parameters, $\beta_{1}, \beta_{2}, r_{1}$ and $r_{2}$, are optimized with stress-strain data at various strain rates. Strain rate sensitivity tests [Lemaitre 1990] are performed in which a specimen is loaded monotonically in strain-control at multiple strain rates, as shown in Fig. 2d.

The material parameter determination procedure, described above, has been applied to as received steel tested at temperatures ranging from $20-700^{\circ} \mathrm{C}$, and is further detailed in references [Chaboche 1989, Lemaitre 1990, Maciejewski 2009, Nouailhas 1987, Nouailhas 1989, Zaki 2000]. The material constants from the above procedure are given in Table 1 for each temperature condition.

Table 1: Material parameters for as received A572 Grade 50 low carbon steel tested at temperatures ranging from $20^{\circ} \mathrm{C}$ to $700^{\circ} \mathrm{C}$.

\begin{tabular}{|c|c|c|c|c|c|}
\hline $\begin{array}{c}\text { Temperature/ } \\
\text { Thermal History }\end{array}$ & $20^{\circ} \mathrm{C}$ & $300^{\circ} \mathrm{C}$ & $500^{\circ} \mathrm{C}$ & $600^{\circ} \mathrm{C}$ & $700^{\circ} \mathrm{C}$ \\
\hline $\mathrm{E}(\mathrm{GPa})$ & 188 & 172 & 127 & 93 & 58 \\
\hline $\mathrm{k}(\mathrm{MPa})$ & 100 & 71 & 27 & 11 & 3 \\
\hline $\mathrm{a}_{1}(\mathrm{MPa})$ & 137 & 96 & 54 & 36 & 22 \\
\hline $\mathrm{C}_{1}$ & 1411 & 1411 & 1411 & 1411 & 1411 \\
\hline $\mathrm{a}_{2}(\mathrm{MPa})$ & 1864 & 1753 & 1111 & 566 & 175 \\
\hline $\mathrm{C}_{2}$ & 1.15 & 1.15 & 1.15 & 1.15 & 1.15 \\
\hline $\mathrm{b}$ & 78 & 78 & 78 & 78 & 78 \\
\hline $\mathrm{Q}_{\max }(\mathrm{MPa})$ & 86 & 78 & 31 & 1 & -10 \\
\hline$\mu$ & 1447 & 1447 & 1447 & 1447 & 1447 \\
\hline $\mathrm{n}$ & 14 & 14 & 14 & 14 & 14 \\
\hline $\mathrm{K}(\mathrm{MPa})$ & 155 & 349 & 304 & 227 & 107 \\
\hline$\alpha$ & $5.5 \mathrm{E}+06$ & $5.0 \mathrm{E}+06$ & $1.0 \mathrm{E}+05$ & $4.5 \mathrm{E}+00$ & $9.9 \mathrm{E}-01$ \\
\hline$\beta_{1}\left(\mathrm{~Pa}{ }^{2.58}\right)$ & $1.0 \mathrm{E}-21$ & $9.9 \mathrm{E}-20$ & $1.0 \mathrm{E}-15$ & $1.0 \mathrm{E}-15$ & $1.0 \mathrm{E}-15$ \\
\hline$\beta_{2}\left(\mathrm{~Pa}{ }^{2.15}\right)$ & $4.6 \mathrm{E}-26$ & $2.1 \mathrm{E}-16$ & $1.0 \mathrm{E}-12$ & $1.0 \mathrm{E}-12$ & $1.0 \mathrm{E}-12$ \\
\hline $\mathrm{r}_{1}$ & 2.58 & 2.58 & 2.58 & 2.58 & 2.58 \\
\hline $\mathrm{r}_{2}$ & 2.15 & 2.15 & 2.15 & 2.15 & 2.15 \\
\hline
\end{tabular}

Several of the material constants, as described above, are temperature-dependent. The material constants have been determined for five different temperatures, ranging from room temperature to $700^{\circ} \mathrm{C}$. A linear interpolation to the material constants is generally used to extend a constitutive model working for any temperature, which may be 
less accurate. A nonlinear form better describes the temperature span, and the formula used to fit the temperature-dependent material constants is given below:

$$
C=A * \tanh \left(-\left(T / T_{0}\right)^{m}\right)+C_{0}
$$

Where $C$ and $T$ represent a material constant and temperature respectively, $A, m, T_{0}$, $C_{0}$ are unknown parameters which are figured out by curve fitting to $C-T$ data.

Fig. 3 shows two examples of the curve-fitting to the temperature-dependent Young's modulus and strain-rate sensitivity coefficient using the equation (11).

Figure 3. Modeling of temperature-dependent material constants (a) Young's modulus, (b) isotropic hardening coefficient, $\mathbf{Q}_{\max }$.

The saturation of material constants at lower temperature was captured by the hyperbolic tangent function of temperature. The saturation values are defined by the parameters, $A$ and $C_{0}$. The sensitivity of the material constant change with temperature is defined by the exponent, $m$. The reference temperature, $T_{0}$, defines the temperature at the middle of the transitional segment of the curve. The parameters for temperature-dependent material constants are listed in Table 2.

Table 2. Parameters in the formula for temperature-dependent material constants

\begin{tabular}{|c|c|c|c|c|}
\hline Constant & $A$ & $T_{0}$ & $C_{0}$ & $m$ \\
\hline$E$ & 187850.1 & 742.0 & 187743.8 & 2.8 \\
\hline$k$ & 100.6 & 520.8 & 99.6 & 2.3 \\
\hline$a_{1}$ & 137.4 & 621.3 & 137.5 & 1.6 \\
\hline$a_{2}$ & 1830.5 & 619.1 & 1864.3 & 3.9 \\
\hline$Q_{\max }$ & 97.7 & 558.0 & 86.1 & 4.1 \\
\hline$K$ & 351.7 & 720.1 & 351.5 & 5.4 \\
\hline$\alpha$ & $5.5 \mathrm{E}+06$ & 437.3 & $5.5 \mathrm{E}+06$ & 6.4 \\
\hline$\beta_{1}$ & $-1.0 \mathrm{E}-15$ & 443.0 & $2.7 \mathrm{E}-27$ & 18.8 \\
\hline$\beta_{2}$ & $-1.0 \mathrm{E}-12$ & 443.0 & $3.2 \mathrm{E}-24$ & 18.8 \\
\hline
\end{tabular}

The temperature dependent and independent material constants are used to fully define the viscoplastic constitutive model. This model is then implemented in finite element 
software to describe the material behavior under varying loading and temperature conditions.

\section{Validation of UMAT code}

The viscoplastic constitutive equations have been implemented into ABAQUS through a subroutine UMAT. A finite element model of uniaxial fatigue specimen was built to simulate the experimental tensile and fatigue tests. A comparison of experimental and numerical stress-strain curves is used to examine the implementation of the simulation model. A quarter 3D finite element model is shown in Fig. 4. The diameter of the cylindrical specimen is $6.35 \mathrm{~mm}$ and the gauge length is $10 \mathrm{~mm}$. The block element with 8 nodes was used to mesh the geometry model. Nodes on the bottom plane were fixed in vertical direction, and symmetry boundary conditions were applied to the nodes on two side planes. To simulate the tensile tests, Nodes on the top plane were subjected to a displacement ramping from 0 to $0.1 \mathrm{~mm}$ within 2000 seconds. 4 simulation cases were done by assigning 4 different uniform temperatures to the whole model. The predicted stress-strain curves are shown in Fig. 5 and compared with the experimental results which show good agreement.

Figure 4. FE model of tensile tests stress-strain curves

Figure 5. Numerical and experimental

The quarter cylinder model was also used for the simulation of a fatigue test at $300^{\circ} \mathrm{C}$. A cyclic displacement loading (see Fig. 6a) was applied to the nodes on the top plane.

\section{Figure 6. (a) Cyclic strain loading in fatigue tests, (b) experimental and numerical hysteresis stress-strain curves at $300^{\circ} \mathrm{C}$}

The magnitude of applied displacement equals the value that the gauge length of the model times the strain that the element was subjected to. The displacement loading shows three strain ranges, $\pm 0.2 \%, \pm 0.3 \%$ and $\pm 0.4 \%$. 4 cycles were run under strain range $\pm 0.2 \%, 6$ cycles under strain range $\pm 0.3 \%$, and 3 cycles under strain range $\pm 0.4 \%$. The cyclic test of three strain ranges used the same loading strain rate of $5 \times 10^{-6} \mathrm{~mm} / \mathrm{mm} / \mathrm{sec}$. The period of one cycle under strain range $\pm 0.2 \%$ is 1600 seconds, 2400 seconds under strain range $\pm 0.3 \%$, and 3200 seconds under strain range $\pm 0.4 \%$. The element stresses in vertical direction were output and plotted with the strains in the same direction. Both experimental and numerical hysteresis stress-strain curves are shown in Fig. 6b. The good agreement of experimental and numerical stress-strain curves validates the implementation of the UMAT code. 


\section{Finite element analysis and results}

\subsection{Simulation of single steel beam}

Numerical simulations were conducted using two finite element models, a simple model of single steel beam and a complex model of steel-framed structure. Simulation of single steel beam

Single steel beam model (Fig. 7) was built to examine effects of loading rate and temperature on the beam deflection.

\section{Figure 7. Single steel beam model}

The two-dimensional beam is $3 \mathrm{~m}$ long and $0.2 \mathrm{~m}$ high. The element type of plain strain was assigned to all elements. Each element has a size of $0.1 \mathrm{~m}$ long, $0.02 \mathrm{~m}$ high. Uniform temperature field was applied to the beam and two temperature cases, $300^{\circ} \mathrm{C}$ and $700^{\circ} \mathrm{C}$, were studied. Uniform pressure ramping up with time was also applied on the beam. Two cases of pressure ramping rate were investigated; $1.5 \mathrm{MPa} / \mathrm{min}$ and $0.15 \mathrm{MPa} / \mathrm{min}$.

The beam deflections from the 4 simulation cases described above are compared in Fig. 8. which shows the evolution of the maximum beam deflections along with the ramping pressure.

\section{Figure 8. Beam deflection at two loading rates (a) at temperature $300^{\circ} \mathrm{C}$ (b) at temperature $700^{\circ} \mathrm{C}$}

Fig. 8a compares the beam deflections generated at $300^{\circ} \mathrm{C}$ for two different pressure ramping rates while Fig. $8 \mathrm{~b}$ shows the comparison at $700^{\circ} \mathrm{C}$. At the temperature $300^{\circ} \mathrm{C}$, the beam deflection is not dependent on the loading rate, however it shows dependency at the temperature $700^{\circ} \mathrm{C}$. This result indicates that the $300^{\circ} \mathrm{C}$ is below the transition temperature of the material strain-rate sensitivity. If we compare the beam deflections under the same pressure load but at the two different temperatures, it becomes obvious that the beam deflection is larger at $700^{\circ} \mathrm{C}$. The higher temperature reduces the strength of the material steel or the stiffness of the steel beam.

\subsection{Simulation of steel-framed structure under fire condition}

Finite element analysis of steel-framed structures under fire condition uses a sequentially coupled thermal-stress analysis [ABAQUS inc. 2006]. In this analysis, a transient heat transfer analysis is first performed to obtain temperature distribution history, and then a stress/deformation analysis is conducted to obtain structural deformation. Nodal temperatures are calculated in the transient heat transfer analysis and stored as a function of time in the heat transfer result file. The stress analysis uses the same geometry model with the same meshing as the heat transfer analysis. The temperature fields for the stress analysis are coupled with temperature results from transient heat transfer analysis.

A three-dimensional model of a multi-story structure was built, the dimensions of which are shown in Fig. 9. 


\section{Figure 9. Modeling of 3D steel-framed structure under fire condition}

The structure has 2 cells with 8 box-shape columns and 8 I-shape beams. Each column is 12 meters high and each beam is 15 meters long. The dimensions of the column and beam cross-sections are shown in Fig. 9. We consider the beams and columns to be integral. 8-node block elements were used to mesh the structure as shown in Fig. 10.

\section{Figure 10. Meshing of FE model of 3D steel-framed structure}

The element size is 0.5 meter in longitude direction of beam and column, and less than 0.04 meter in their transverse direction. The total number of elements is 19136.

\subsubsection{Heat transfer analysis}

The finite element model was first employed to conduct transient heat analysis. The material properties required for heat transfer analysis are shown in Table 3.

Table 3. Material properties for heat transfer analysis

\begin{tabular}{|c|c|c|}
\hline Mass Density & Thermal Conductivity & Specific Heat \\
\hline $7800 \mathrm{~kg} / \mathrm{m}^{3}$ & $50 \mathrm{~J} / \mathrm{m}^{2}{ }^{\circ} \mathrm{C}$ & $470 \mathrm{~W} / \mathrm{kg}^{\circ} \mathrm{C}$ \\
\hline
\end{tabular}

The element type was set as DC3D8 for heat transfer analysis. The room temperature $25^{\circ} \mathrm{C}$ was assigned to the steel-frame structure as the initial condition. A surface heat flux of $16 \mathrm{~kW} / \mathrm{m}^{2}$ was applied on the bottom plane of one beam in the first floor, and 24 $\mathrm{kW} / \mathrm{m}^{2}$ on the side plane of its connected column in order to simulate the appearance of a fire in the cell (see Fig. 11).

\section{Figure 11. Surface heat flux as thermal loading applied to the structure}

The heat transfer duration is 1 hour. The calculated temperatures at all nodes and at different time are stored in the output file of heat transfer analysis. The output frequency of nodal temperatures is $0.2 \mathrm{~Hz}$.

Fig. 12 shows the temperature distribution after 1 hour of heat transfer. The nonuniform temperatures across the sections of steel frames were observed.

\section{Figure 12. The final temperature distribution in the structure}

The higher temperature occurred to the positions near the surface where external heat flux was applied. Within 1 hour, the heat spread was confined in the mid cell of the first floor. Positions far away from the surface where the heat flux came in almost maintained their initial temperature of $25^{\circ} \mathrm{C}$. Figs. $13-14$ show the temperature history at 7 points on the heated beam's and column's cross-sections, respectively. 


\section{Figure 13. Temperature history of seven points on the beam's cross-section}

\section{Figure 14. Temperature history of seven points on the column's cross-section}

The temperature at the monitored positions increases with time since the continuous heat flow increase the thermal energy of the structure. For the beam, the temperatures at points $\mathrm{B} 1$ and $\mathrm{B} 2$ are higher than those at points B3, B4 and B5, and much higher than those at points $\mathrm{B} 6$ and $\mathrm{B} 7$. For the column, the temperatures at points $\mathrm{C} 1$ and $\mathrm{C} 2$ are higher than those at points $\mathrm{C} 3, \mathrm{C} 4$ and $\mathrm{C} 5$, and much higher than those at $\mathrm{C} 6$ and $\mathrm{C} 7$. Although $\mathrm{B} 1$ and $\mathrm{B} 2$ are on the same heat flux surface, their temperatures are different. The temperature at $\mathrm{B} 1$ is higher than that at $\mathrm{B} 2$ because the position $\mathrm{B} 2$ is nearer to the web, which is the heat transfer path.

\subsubsection{Stress/deformation analysis}

In the stress/deformation analysis, the element type was changed from heat transfer type to stress analysis type C3D8, while the geometry remained the same. The developed UMAT was used as the material model. The four columns were fixed at their roots. A uniform pressure was applied on all beams and temperature field was assigned to the whole structure. The simulation consists of three loading steps. The first step is to increase the uniform pressure from zero to $0.04 \mathrm{MPa}$ in 10 seconds, while keeping the temperature constant at $25^{\circ} \mathrm{C}$. In the second step, the maximum pressure loading is maintained and the temperature field is coupled with the results obtained from the transient heat transfer analysis, and hence the duration of step 2 is 60 minutes. In the third step, both the pressure and temperature distribution in the structure is held constant for 30 minutes. Therefore, static stress/deformation analysis was performed with a time period of 90 minutes plus 10 seconds. The maximum time increment is 0.5 second. The control setting for the nonlinear effect of large displacement was activated in the simulation. The displacement, strain and stress results along with time were output from the stress analysis.

The final deformation of the three-dimensional two-story structure from the stress analysis using the viscoplastic constitutive model, discussed above, was examined. Among the four beams of the first floor, the beam subjected to the heat flux deflected more than other beams as expected. Fig. 15 shows the deflection history of two beams at the first floor (see Fig. 10).

\section{Figure 15. The deflection history at the midspan of the heated and non-heated} beams

The heated beam refers to the beam which had the heat flux applied to it, and the nonheated beam is a beam neighboring the heated beam. In the ten seconds of load step 1, the deflections of the two beams increase quickly due to the increasing pressure load. In this step, the two beams achieved the same amount of deflection due to geometrical symmetry, the same loading condition, and uniform structural temperature. In load step 2 , 
the deflection of the heated beam does not increase at the beginning although its temperatures increase. It is concluded that the beam's deflection starts to increase when the applied load/stress becomes larger than the strength of the beam. The applied load did not change but the beam's strength degraded with the increase of temperature. When the strength of the heated beam degraded below its stress level, the inelastic strain occurred as shown in Fig. 16, and the beam's deflection started to increase slowly initially and then faster with the continuously increasing of the beam's temperature.

Figure 16. Strain and stress history at the midspan of the heated beam

In load step 3, the applied loading and the temperature distribution did not change (actually the applied stress relaxed as shown in Fig. 16), but the heated beam's deflection continued to increase. The deflection increase in load step 3 was attributed to the creep deformation (that is, material strain-rate sensitivity) at elevated temperatures, which can be shown in Fig. 16.

\section{Conclusions}

The work in this paper describes a viscoplastic constitutive model that has been employed to simulate the flow behavior of structural steel A572 grade 50 steel at elevated temperatures. The material constants of a the model have been fitted as a function of temperature, thus allowing the implementation of the corresponding constitutive equations in a UMAT subroutine of the ABAQUS platform The validation of the UMAT has been carried out by comparing the experimental data with those obtained from the numerical simulations under the same applied load conditions. The finite element analysis of a three-dimensional steel-framed structure under fire condition has been performed using a simulation strategy of sequentially coupled thermal-stress analysis. The general conclusions of this study can be listed as follows:

1. The nonlinear material behavior of the low carbon structural steel at elevated temperatures can be captured by unified constitutive equations, which consist of a nonlinear kinematic hardening model and a hyperbolic function for the modeling of temperature-dependent material constants.

2. The steel shows a transition temperature for the time-dependent plastic deformation. The strain-rate sensitivity transition is indicated by the trend of temperaturedependent material constants.

3. The heat transfer analysis of the 3D steel-frame structure shows the temperature distributed nonlinearly across the sections of the steel frame and along the length of beams and columns.

4. As the temperature increases, large bending or buckling deformation could occur to the steel-frame structure as a result of the degradation of the material's strength below the applied stress level.

5. The time-dependent material behavior contributes to the structure's bending or bucking when the applied temperature is higher than the strain-rate sensitivity transition temperature. 


\section{Acknowledgments}

This work has been supported by FM Global and the Department of Homeland Security Center of Excellence: Explosives Detection, Mitigation, and Response at the University of Rhode Island

\section{References}

ABAQUS Inc. (2006). ABAQUS Standard User's Manual, 6.6 Edition.

Chaboche, J.L., and Rousselier, G. (1983), On the Plastic and Viscoplastic Constitutive Equations-Part I: Ruled Developed with Integral Variable Concept, Transactions of the ASME, Journal of Pressure Vessel Technology, 105, pp.123-133.

Chaboche, J.L., and Rousselier, G. (1983), On the Plastic and Viscoplastic Constitutive Equations-Part II: Application of Integral Variable Concepts to the 316 Stainless Steel, Transactions of the ASME, Journal of Pressure Vessel Technology, 105, pp. 159-164.

Chaboche, J.L. (1989), Constitutive Equations for Cyclic Plasticity and Cyclic Viscoplasticity, International Journal of Plasticity, 5, pp.247-302.

Kumar P, Nukala VV, White DW., A Mixed Finite Element for Three-Dimensional Nonlinear Analysis of Steel Frames, Comput Methods Appl Mech Engrg, 193, 2004, pp. 2507-2545.

Lemaitre, J., and Chaboche (1990), J.L., Mechanics of Solid Materials, Cambridge University Press, Cambridge, United Kingdom.

Li G.Q., Jiang S.C. (1999), Prediction to Nonlinear Behavior of Steel Frames Subjected to Fire, Fire Safety Journal, 32, pp.347-68.

Liew J.Y., Tang L.K., Holmaas T, Choo Y.S. (1998), Advanced Analysis for the Assessment of Steel Frames in Fire, Journal of Constructional Steel Research, 47, pp.19-45.

K. Maciejewski, Y. Sun, O. Gregory and H. Ghonem (2008), Deformation and Hardening Characteristics of Low Carbon Steel at Elevated Temperature, Material Science and Technology Conference and Exhibition, October 2008, Pittsburgh, Pennsylvania.

Makelainen P, Outinen J, Kesti J. (1998), Fire design model for structural steel S420M based upon transient-state tensile test results, Journal of Constructional Steel Research, 48, pp. 47-57.

Najjar, S.R., and Burgess, I.W. (1996), A Nonlinear Analysis for Three-Dimensional Steel Frames in Fire Conditions, Engineering Structures, 18(1), pp. 77-89.

Nouailhas, D. (1987), A Viscoplastic Modelling Applied to Stainless Steel Behavior, Proceedings of the Second International Conference on Constitutive Laws for Engineering Materials: Theory and Application, January 5-8, Tuscon, Arizona, U.S.A., pp.717-724.

Nouailhas, D.(1989), Unified Modeling of Cyclic Viscoplasticity: Application to Austenitic Stainless Steels, International Journal of Plasticity, 5, pp. 501-520.

Wang, Y.C., Lennon, T., and Moore, D.B. (1995), The Behavior of Steel Frames Subject to Fire, Journal of Constructional Steel Research, 35, pp. 291-322. 
Zaki, A.S., and Ghonem, H. (2000), Modeling the Ratcheting Phenomenon in an Austenitic Steel at Room Temperature, Proceeding of the ASME 2000 Design, Reliability, Stress Analysis and Failure Prevention Conference, Baltimore, Maryland, U.S.A., 


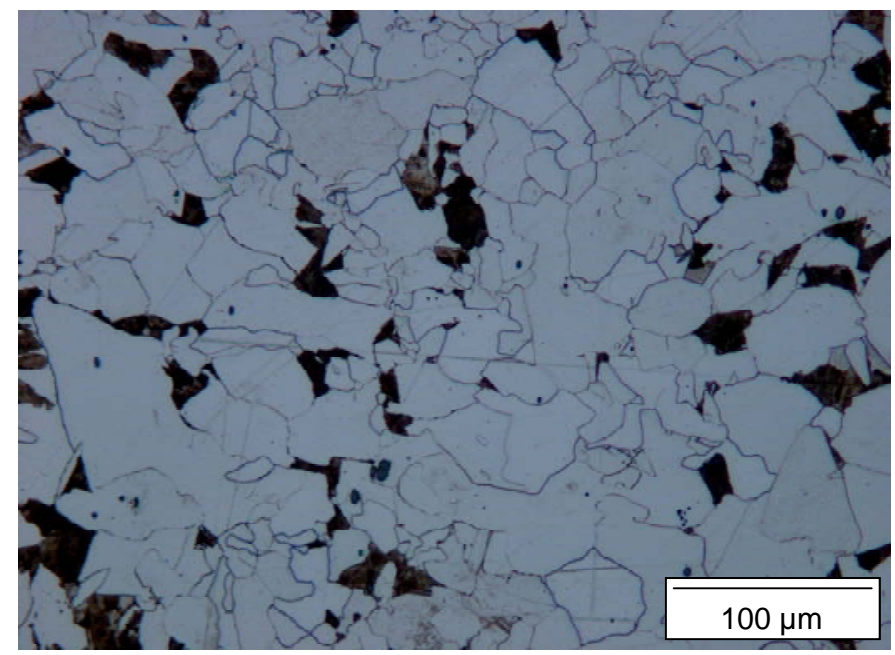

Figure 1. Optical micrograph of as-received A572 grade 50 steel etched for 5 seconds in 5 vol\% nital. The microstructure is typical of normalized steel, consisting of pearlite colonies (dark phase) and alpha-ferrite (light phase) equiaxed grains. The pearlite colonies have a volume fraction of $10 \%$ and the grain size is 53 microns (ASTM 5). 


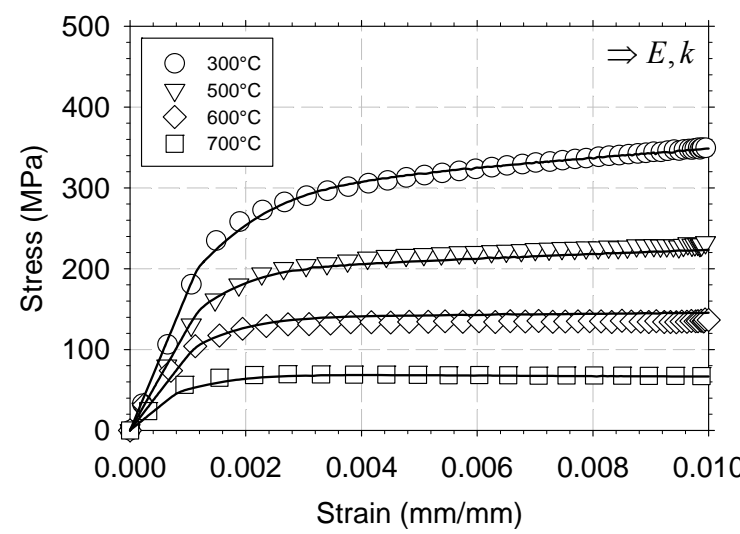

(a)

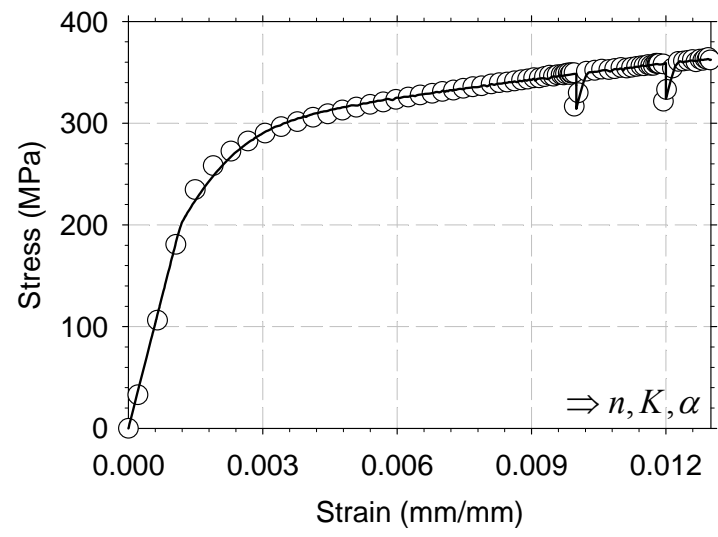

(c)

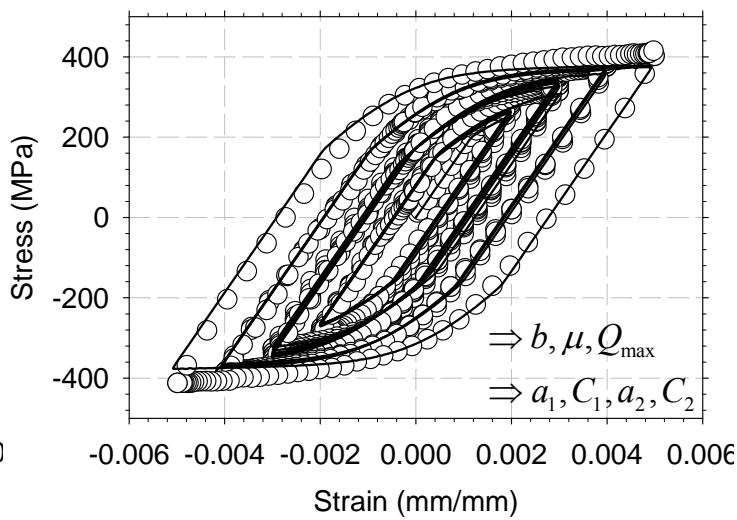

(b)

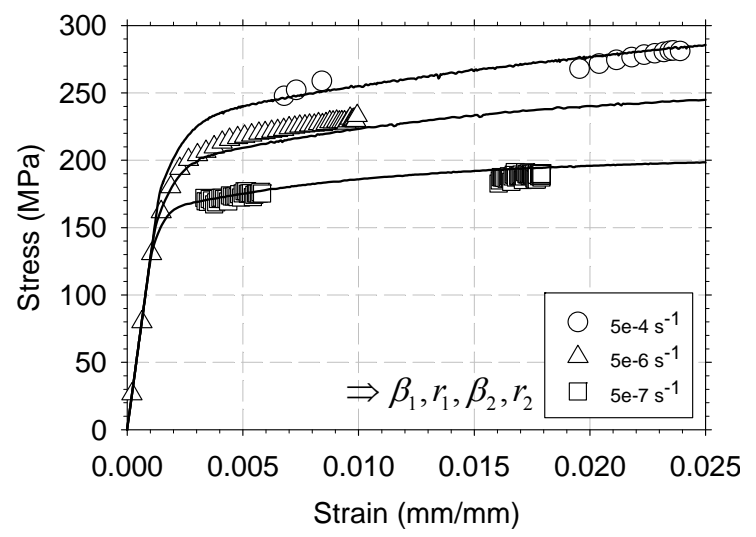

(d)

Figure 2. Experimental (Symbol) and numerical (Solid line) stress-strain curves for low carbon steel tested (a) Monotonic stress-strain curves (b) cyclic stress-strain curves at $300^{\circ} \mathrm{C}$, (c) relaxation stress-strain curves at $300^{\circ} \mathrm{C}$ and (d) monotonic stress-strain curves at multiple strain rates at $500^{\circ} \mathrm{C}$. These curves are used to determine the material parameters specified on the graphs. 


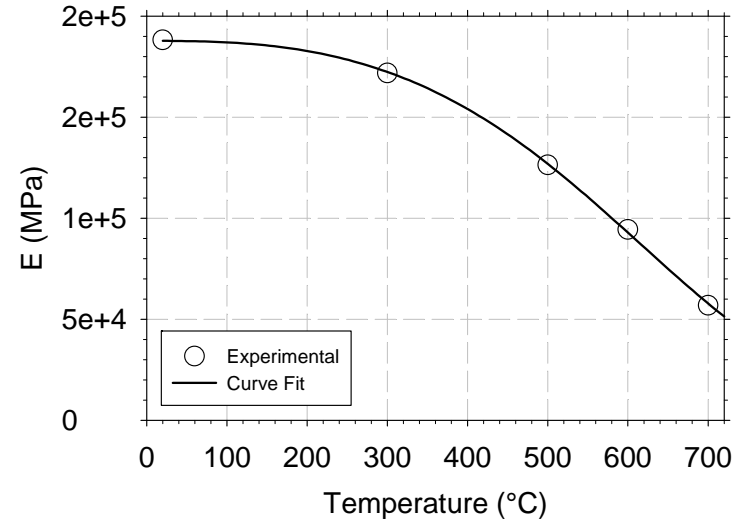

(a)

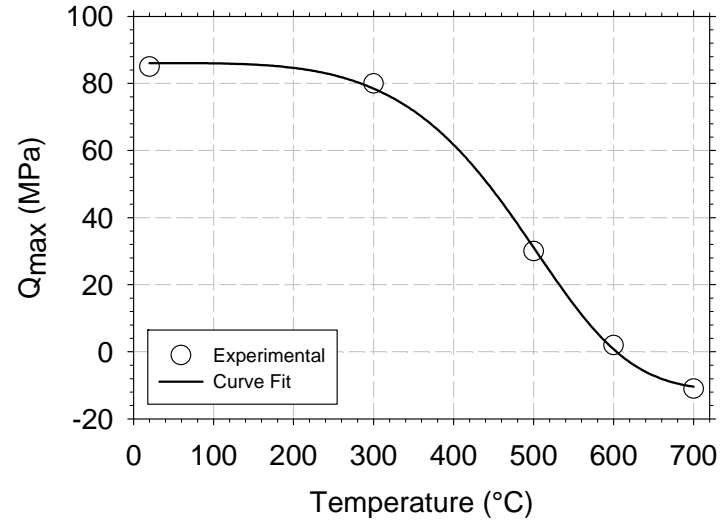

(b)

Figure 3. Modeling of temperature-dependent material constants (a) Young's modulus, (b) isotropic hardening coefficient, $\mathbf{Q}_{\max }$.

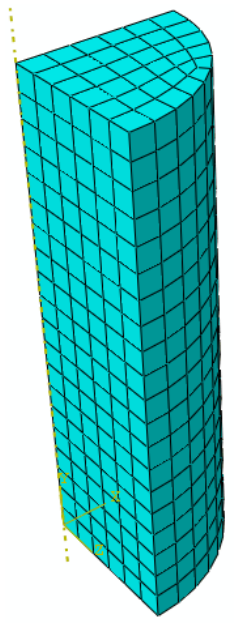

Figure 4. FE model of tensile tests stress-strain curves

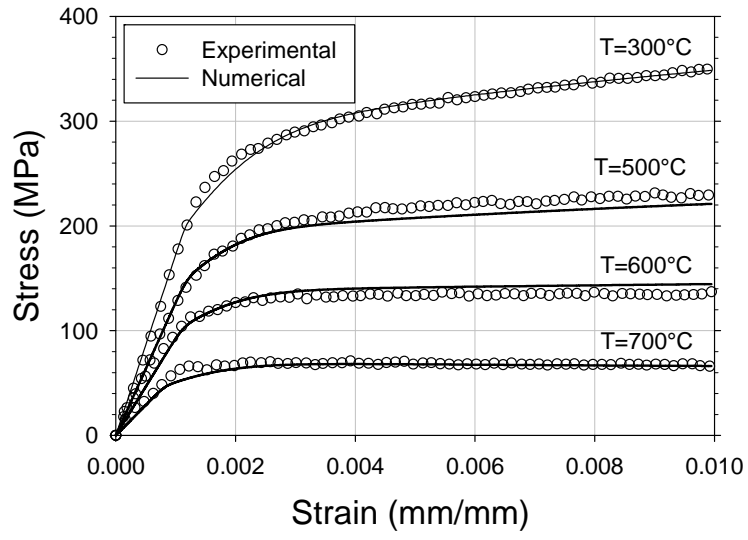

Figure 5. Numerical and experimental 


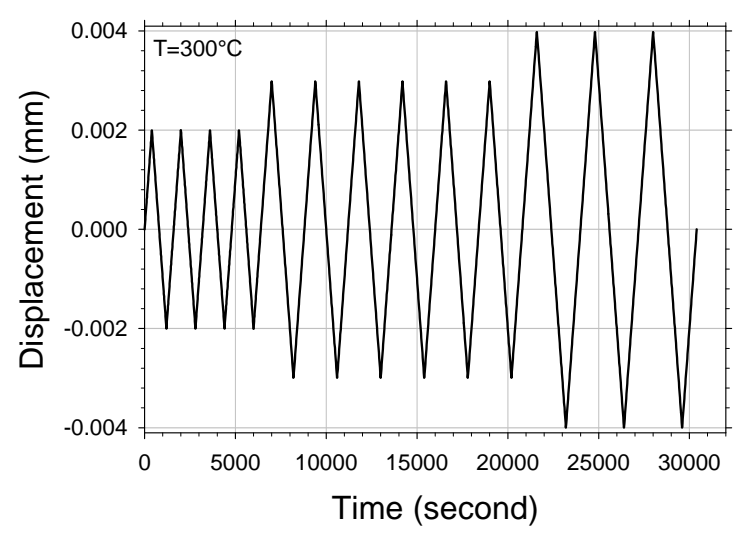

(a)

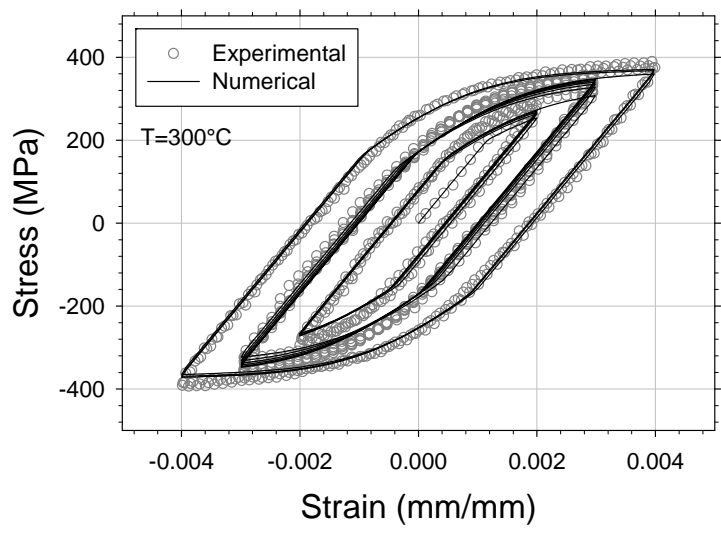

(b)

Figure 6. (a) Cyclic strain loading in fatigue tests, (b) experimental and numerical hysteresis stress-strain curves at $300^{\circ} \mathrm{C}$

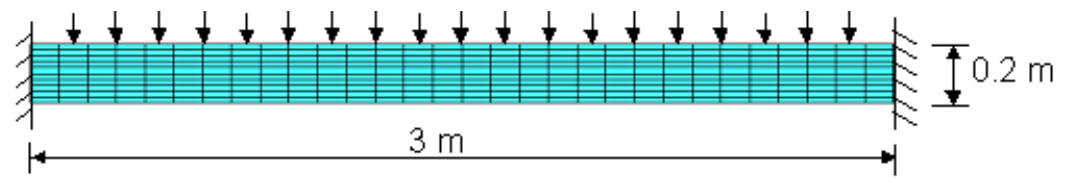

Figure 7. Single steel beam model

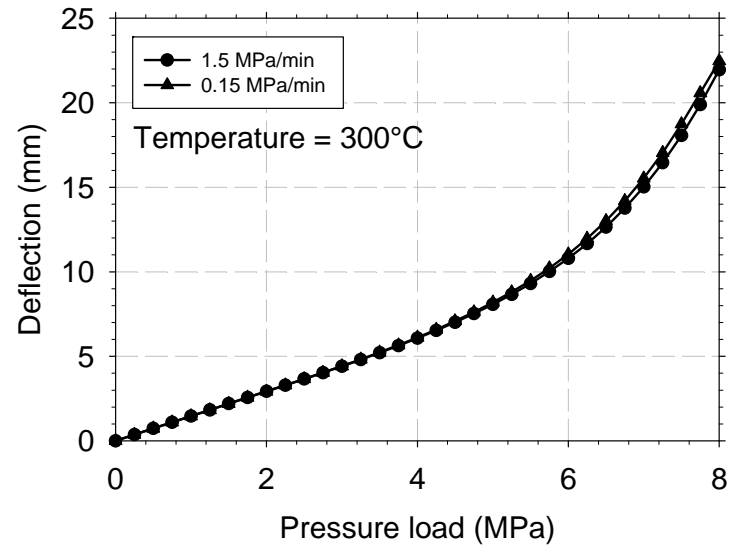

(a)

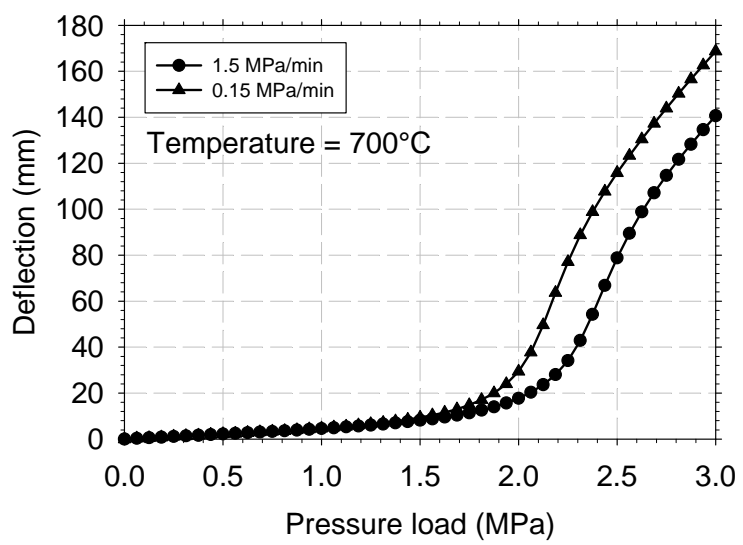

(b)

Figure 8. Beam deflection at two loading rates (a) at temperature $300^{\circ} \mathrm{C}(\mathrm{b})$ at temperature $700^{\circ} \mathrm{C}$ 


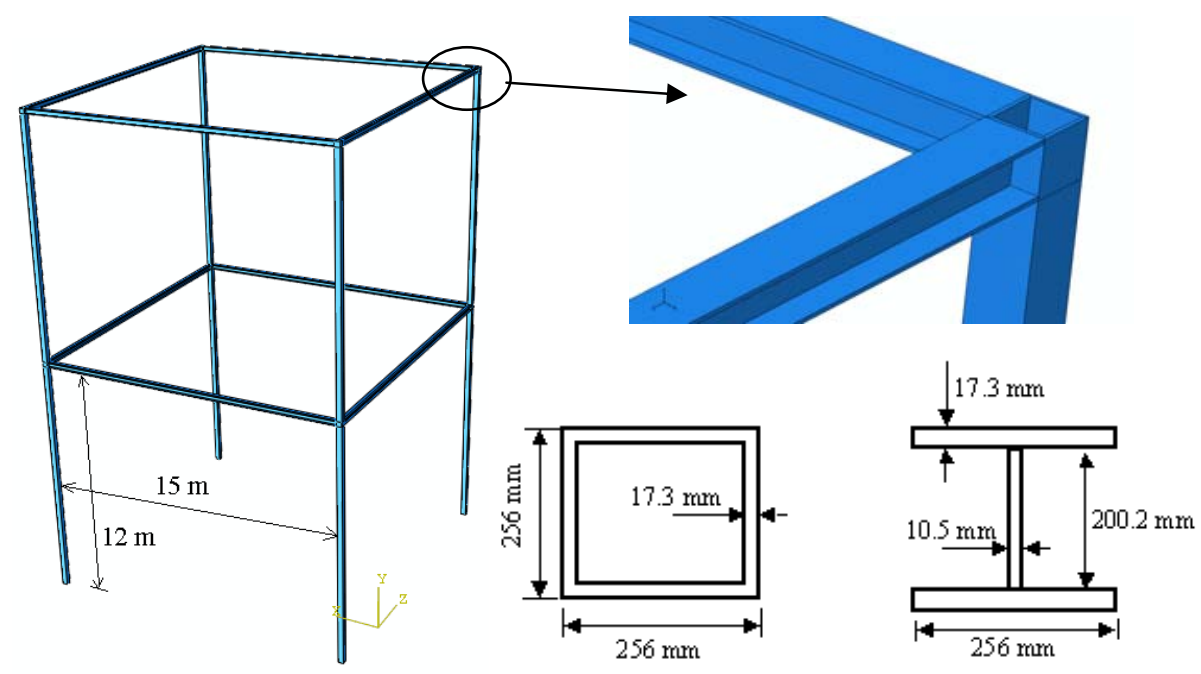

Figure 9. Modeling of 3D steel-framed structure under fire condition

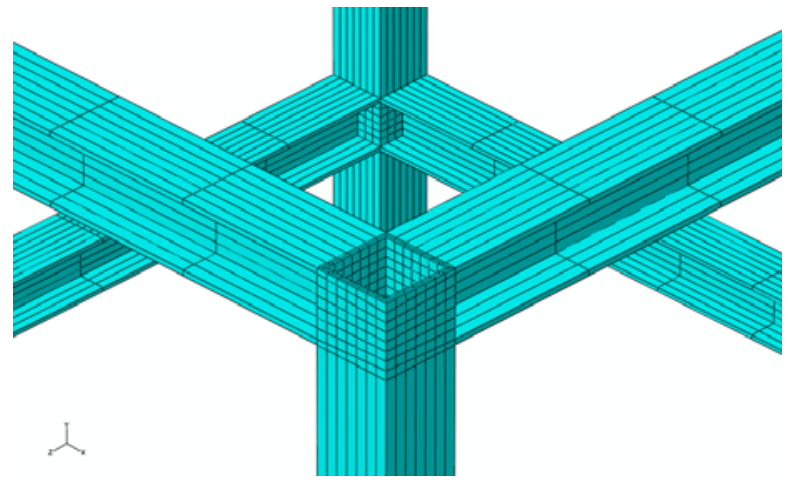

Figure 10. Meshing of FE model of 3D steel-framed structure 


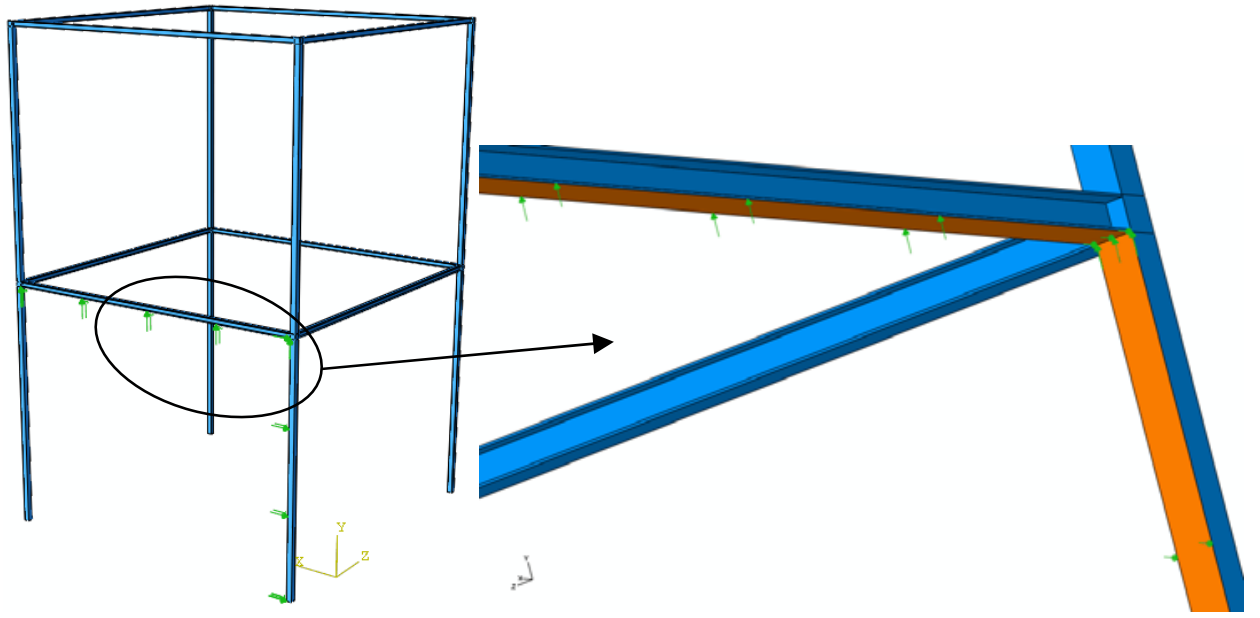

Figure 11. Surface heat flux as thermal loading applied to the structure

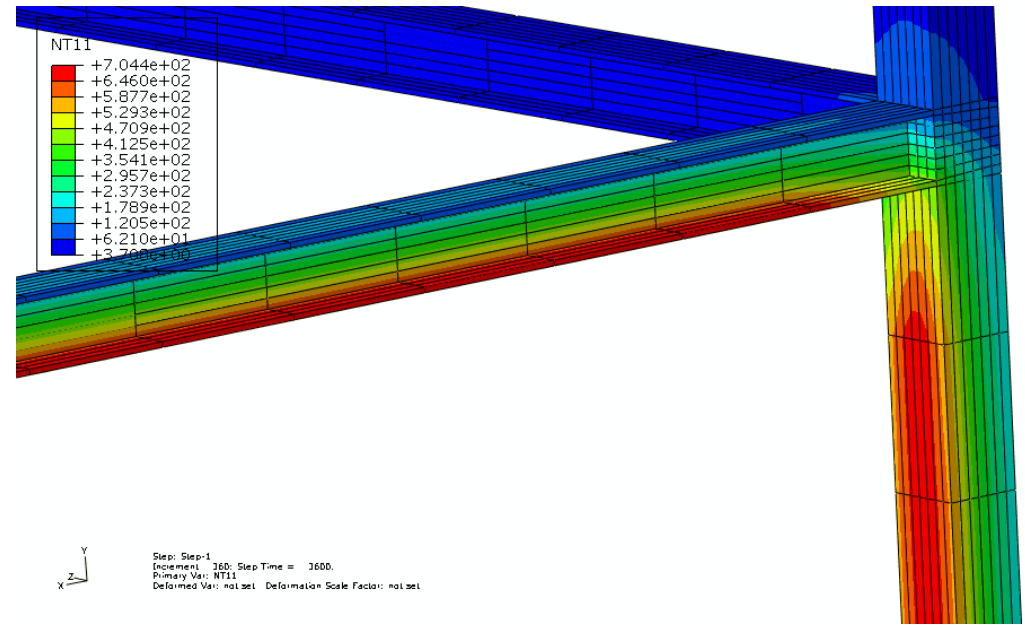

Figure 12. The final temperature distribution in the structure 


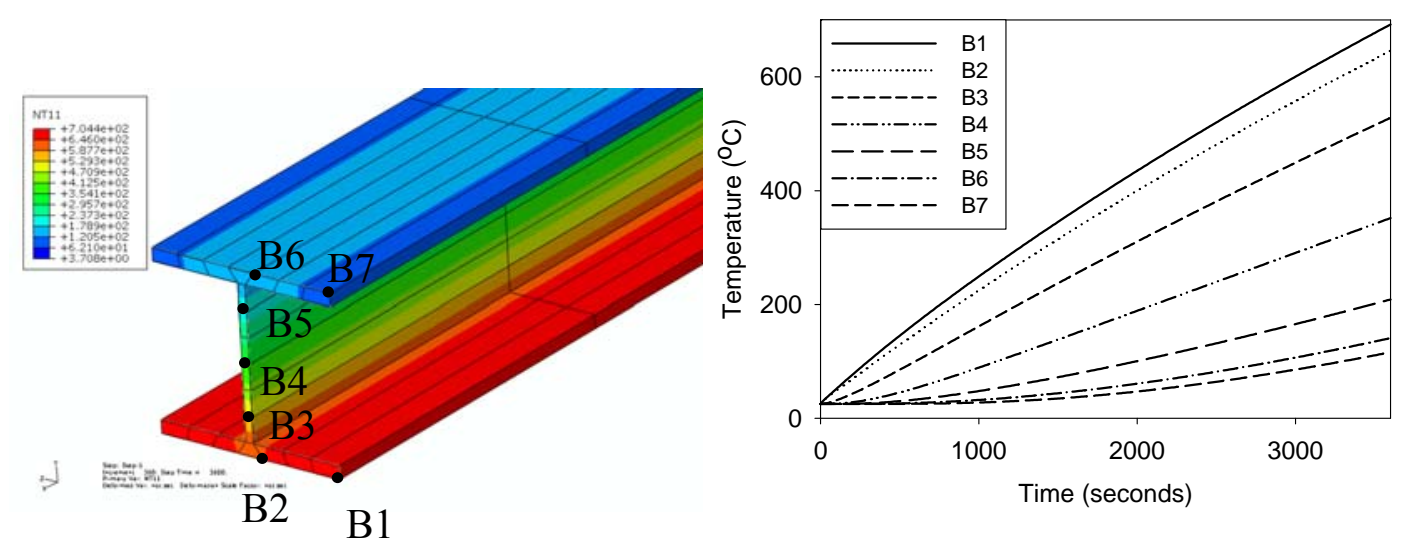

Figure 13. Temperature history of seven points on the beam's cross-section
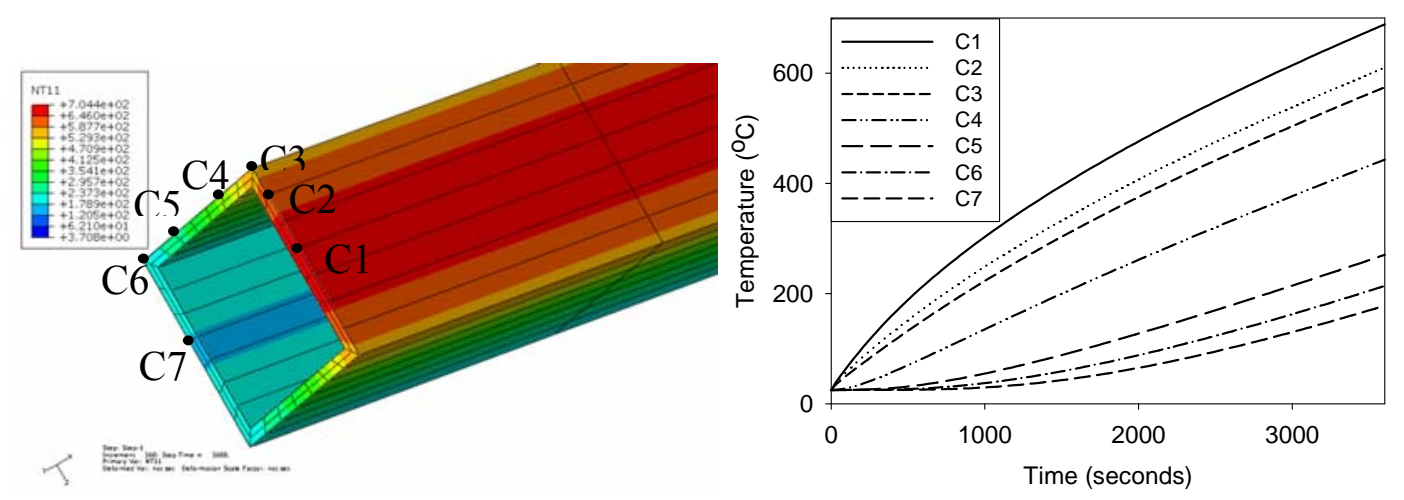

Figure 14. Temperature history of seven points on the column's cross-section 


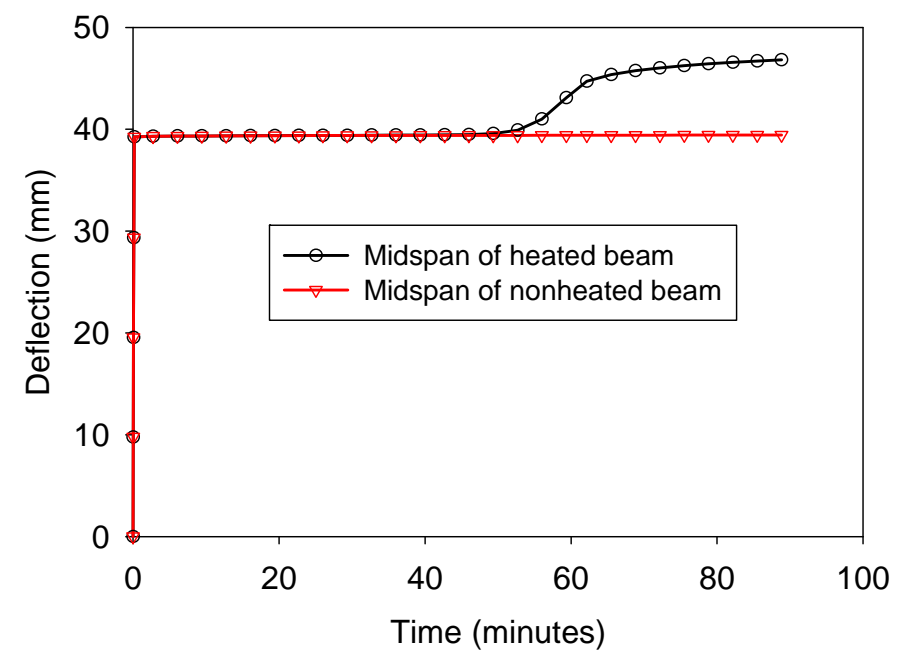

Figure 15. The deflection history at the midspan of the heated and non-heated beams

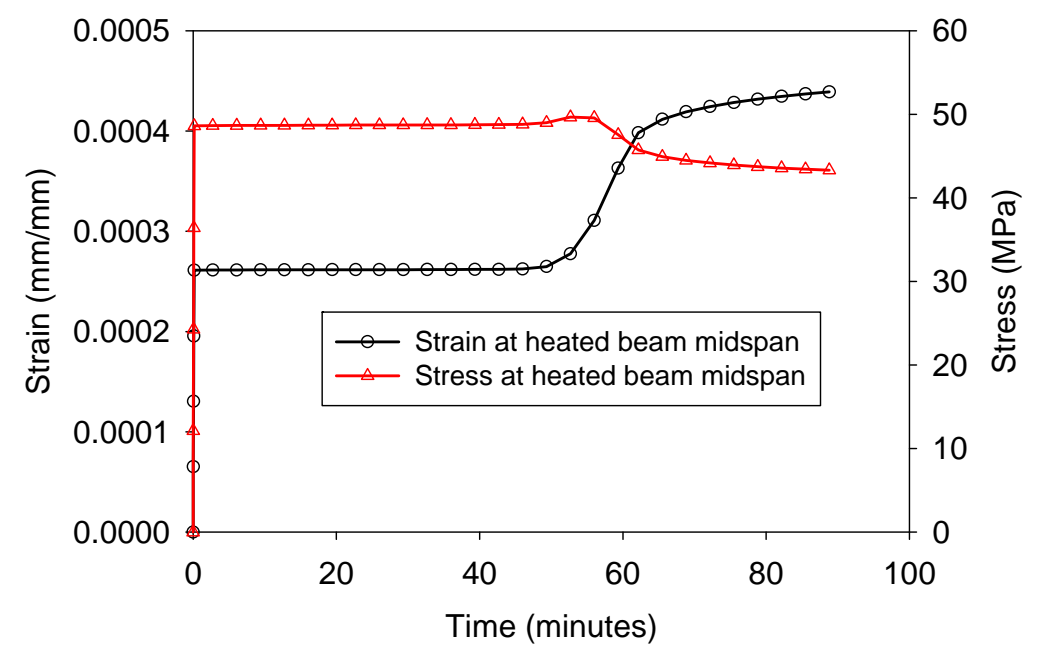

Figure 16. Strain and stress history at the midspan of the heated beam 